\title{
La aldea perdida, de Palacio Valdés, alegato anti-industrialista
}

\author{
JOSÉ LUIS RAMOS GOROSTIZA
}

Universidad Complutense de Madrid, Facultad CC.EE., Campus de Somosaguas, 28223 Pozuelo de Alarcón (Madrid),España.E-mail: ramos@ccee.ucm.es

\section{RESUMEN}

En La aldea perdida (1903), de Armando Palacio Valdés, encontramos un buen muestrario de los principales planteamientos anti-industrialistas del momento. De hecho, la novela enlaza con el anti-industrialismo "fin de siglo" y también con los recelos del catolicismo social español frente al mundo industrial. Sin embargo, su fuerte componente anti-industrialista quedó muy difuminado en la adaptación cinematográfica llevada a cabo por Sáenz de Heredia en 1948, en pleno primer franquismo: eran años en los que la retórica oficial agrarista se combinaba con una orientación abiertamente industrial de la política práctica.

Palabras clave: Anti-industrialismo, economía y literatura, Palacio Valdés, La aldea perdida.

\section{Palacio Valdés' La aldea perdida, a Plea Against Industrialism}

\begin{abstract}
In Palacio Valdés' La aldea perdida (1903) it can be found a good sampling of the major anti-industrialist issues of the moment. In fact, the novel is linked to the fin de siècle anti-industrialism and also to the distrust towards the industrial world of Spanish Social Catholicism. However, its strong antiindustrialist component was diminished in the film adaptation done by Sáenz de Heredia in 1948, during the early Franco period: in these years the official agrarian rhetoric was combined with an openly industrial orientation of practical politics.
\end{abstract}

Keywords: Anti-Industrialism, Economics and Literature, Palacio Valdés, La Aldea Perdida.

Clasificación JEL: B00, Z10

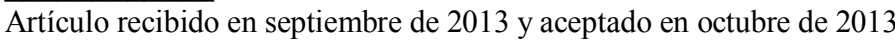

Artículo disponible en versión electrónica en la página www.revista-eea.net, ref. ə-32104 


\section{INTRODUCCIÓN}

Armando Palacio Valdés (1853-1938) fue uno de los novelistas españoles de mayor éxito del primer tercio del siglo XX, llegando a convertirse en "un clásico vivo", como le definió el exigente crítico Azorín ${ }^{1}$. Dos veces propuesto para el premio Nobel, en 1927 y 1928, sus obras alcanzaron una enorme popularidad y se tradujeron a numerosos idiomas europeos (inglés, francés, alemán, ruso, holandés, sueco, eslovaco, finés, etc.). De hecho, al haber sido muy traducido, especialmente al inglés, es probablemente uno de los escritores españoles de finales del siglo XIX y principios del XX -junto con Blasco Ibáñez y Galdósque ha sido más accesible y leído en el extranjero ${ }^{2}$.

Como señala Álvaro Ruiz de la Peña (2003: 29-30), diversos indicadores nos hablan de su fama en la España de los años veinte: por ejemplo, en 1925 el dramaturgo Rivas Cherif pidió a algunos escritores que indicaran el nombre de siete novelistas españoles con los que se pudiera iniciar en nuestra literatura a una extranjera culta, y Palacio Valdés apareció en doce de las veinticinco respuestas recibidas; y en $1927 \mathrm{El} \mathrm{Sol}$ encuestó a quinientas lectoras sobre su novelista preferido, y Palacio Valdés fue el cuarto más votado, tras Galdós, Cervantes y Concha Espina. Por otra parte, por entonces se sucedían los homenajes al escritor, se reeditaban sus obras, se le realizaban múltiples encargos, se llevaban al cine algunas de sus novelas más famosas (como José en 1925 o La Hermana San Suplicio en 1927), se le otorgaban las más altas distinciones (como la Legión Francesa), se le nombraba miembro de ilustres corporaciones internacionales (como la Royal Society of Literature of the United Kingdom o la Société des Gens de Lettres de France), o se daba su nombre a calles, plazas, cines y teatros, e incluso a un casino de literatos en la lejana Kansas.

Sin embargo, precisamente en estos mismos años veinte la crítica española más progresista y los escritores más jóvenes veían la obra del asturiano con total indiferencia, cuando no con absoluto desprecio, considerándola completamente caduca y huera, además de ideológicamente reaccionaria. De esta forma, se daba la paradoja de que el escritor de mayor éxito popular de la época junto a Blasco Ibáñez, era sin embargo relegado por buena parte de la crítica especializada y las élites intelectuales. De hecho, tras la muerte del autor sus cuentos y novelas fueron cayendo en el olvido, y sólo en tiempos relativamente recientes han comenzado a ser recuperados. Parte de la incomprensión hacia la obra de Palacio Valdés quizá haya estado relacionada con su compleja evolución personal, desde un naturalismo matizado en su primera etapa (1881-1893) hasta el

\footnotetext{
${ }^{1}$ Casamayor (1998: 33).

2 En internet, dentro del Proyecto Gutenberg (http://www.gutenberg.org/browse/authors/ p\#a4015), hay un buen muestrario de obras de Palacio Valdés, bastantes también en su versión inglesa.
} 
notorio conservadurismo de la última (1900-1928), pasando entremedias por una profunda crisis espiritual (1893-1899). De esta forma, nada quedaba en el último Palacio Valdés de sus iniciales posiciones racionalistas, anti-clericales y anti-aristocráticas.

La aldea perdida (1903) se inscribe en la etapa de creciente conservadurismo del autor. Aunque caben muchas posibles lecturas de la novela, la económica reviste un particular interés. Al margen de cuáles sean los méritos literarios de la obra, lo que se pretende subrayar aquí es que constituye uno de los alegatos anti-industrialistas más explícitos de la literatura española. De hecho, como se intentará mostrar en este trabajo, recoge en gran medida los temas centrales del anti-industrialismo de la época (el conflicto naturaleza-progreso, la oposición campo-ciudad, el ensalzamiento de la actividad agrícola frente a la industrial, etc.) y conecta con las dos principales corrientes anti-industrialistas del momento: por un lado, con el anti-industrialismo "fin de siglo" -pues en la novela se aprecia una clara influencia modernista-, y por otro, con el matizado anti-industrialismo del catolicismo social español -una de cuyas figuras más destacadas, el canónigo ovetense Maximiliano Arboleya, fue gran amigo de Palacio Valdés-. Es decir, La aldea perdida puede ser calificada de ejemplo paradigmático de la reacción anti-industrialista en la España de comienzos del siglo XX. Su carácter es además, en cierta medida, autobiográfico: el escritor, cuya primera infancia transcurrió en la aldea de Entralgo -ubicada en el valle de Laviana- asistió al brutal impacto que produjo la industrialización del concejo entre 1860 y 1870 , con la rápida ruptura de los modos, usos y costumbres ancestrales propios de la vida campesina. Fue esta experiencia personal la que sin duda aprovechó para confeccionar el trasfondo del relato, que transcurre precisamente en el escenario geográfico de su infancia.

Cuarenta y cinco años después de su publicación, en 1948, en plena etapa del primer franquismo y cuando el régimen exaltaba todavía formalmente los valores agraristas, el cineasta José Luis Sáenz de Heredia llevó a la pantalla una adaptación de la citada obra de Palacio Valdés, bajo el título "Las aguas bajan negras". Sin embargo, aunque en el largometraje se apuntaba el conflicto entre la Asturias tradicional campesina y la minera, éste quedaba muy difuminado respecto a la novela, al tiempo que la trama se adornaba con elementos ajenos a ella que atemperaban mucho la fuerte carga anti-industrialista del texto original, tal como se verá al final de este artículo.

\section{LAS CORRIENTES ANTI-INDUSTRIALISTAS EN EL CAMBIO DE SIGLO Y SU CONEXIÓN CON $L A A L D E A$ PERDIDA}

La aldea perdida. Novela-poema de costumbres campesinas se publica en 1903, precisamente en un periodo, entre finales del siglo XIX y principios del 
XX, en el que las ideas de Thomas Carlyle, John Ruskin y William Morris -que habían desarrollado la crítica romántica al capitalismo industrial por su creación de miseria y fealdad estética y de una sociedad fragmentada, inhumana y hostil, basada exclusivamente en el vínculo monetario- empiezan a tener una notable difusión en Europa, incluida España ${ }^{3}$. Es también el momento de la llamada crisis "fin de siglo" dominada por el pesimismo nietzscheano, que se traduciría en claros síntomas de insatisfacción y desencanto en los círculos literarios y artísticos europeos frente a los valores pragmáticos y utilitarios de la sociedad burguesa del gran capitalismo, poniendo en tela de juicio el cientifismo, el positivismo, el materialismo, y la idea misma de progreso ${ }^{4}$.

En España, el anti-industrialismo "fin de siglo" se concretó especialmente en el Modernismo catalán y en algunas obras de autores como Cebrià de Montoliu, intelectuales del 98 como Unamuno, Baroja, Azorín y Valle-Inclán, o escritores de la generación del 14 como Gabriel Miró ${ }^{5}$. Pero también encontraron cierto reflejo en nuestro país diversas reacciones frente a la civilización industrial que se dieron asimismo en toda Europa, tales como el medievalismo, la revalorización del mundo rural y de las formas de vida tradicionales, el cuestionamiento de la ciudad moderna, la nueva sensibilidad hacia la naturaleza, o el renacimiento de las artes manuales y los oficios artísticos -que a su vez reflejaba el sueño de una vuelta al sistema artesanal y a ciertos ideales culturales y estéticos-. En definitiva, "el anti-industrialismo fin de siècle fue sobre todo en España, como en otros países europeos, un difuso clima de opinión con múltiples

\footnotetext{
3 Sobre la crítica al industrialismo en Carlyle, Ruskin y Morris véanse Martínez Sahuquillo (1994), Wiener (1981: 31-39), y Ramos Gorostiza y Martínez Vara (2011: 276-279). La influencia de Ruskin y Morris en España ha sido estudiada por Litvak (1980: 20-27). Entre los autores españoles que se interesaron por Ruskin están Unamuno -que también tradujo a Carlyle, Joan Maragall, Fernando Araujo, Adolfo Posada y Cebrià de Montoliu. Además de traducciones de sus obras, se publicaron artículos sobre él en revistas como La España Moderna, La Revista Blanca, Revista Contemporánea, Natura, Catalunya, Nuestro Tiempo, o La Ilustración Artística. En cuanto al interés por Morris, cabe citar autores como Unamuno y Buylla, además de los círculos libertarios -donde se traducen algunos de sus textos- y revistas de arte y pensamiento tales como L'Avens, La Ilustración Ibérica, Luz o Joventut. Con todo, la mayor influencia de Morris -que debe ser en cualquier caso matizada- se produjo en el Modernismo catalán y en la renovación de las artes decorativas y el diseño (Calvera, 1997: 231-252). Sobre el modernismo arquitectónico como reacción anti-industrialista, Lluch (1997). En español pueden consultarse, como representativas de las ideas socioeconómicas de Ruskin y Morris, Ruskin (2002) y Morris (1977 y 2004). En el caso de Carlyle no existe aún traducción al español de una selección representativa de sus textos, tal como pueda ser por ejemplo Carlyle (1971)

${ }^{4}$ Véase Mayer (1984: 251-272). Esta etapa europea de "crisis de la razón", en la que afloran incertidumbres y contradicciones respecto a un determinado modelo de civilización, va a solaparse en España con el clima regeneracionista y la creciente conciencia colectiva de atraso o fracaso.

${ }^{5}$ Véase Litvak (1980). Sobre la influencia del movimiento prerrafaelista en Miró, Riera (1988).
} 
reflejos en el mundo del arte y la cultura, más que un discurso coherente desarrollado con amplitud y profundidad por autores concretos" 6 .

Pues bien, Ruiz de la Peña (2003: 38) cree que hay poderosos ecos e influencias de la literatura "fin de siglo" en La aldea maldita, reflejos de un modernismo literario que fue "más que cualquier otra cosa, un canto de rebeldía frente al orden impuesto por el pensamiento positivista, una acusación frontalmente dirigida a la sociedad plutocrática del dinero y los negocios". Para este autor, la citada novela de Palacio Valdés se une así a la "reacción espiritualista contra las alineaciones de la modernidad", que en vez de detenerse en la denuncia de una estructura social opresiva, plantea la búsqueda de la Belleza como categoría anti-burguesa. Y como ilustraciones de la presencia del modernismo en la novela señala, por ejemplo, la prosa poética y antirrealista -con abundantes símbolos de raíz clasicista, expresiones arcaizantes y referencias al mundo mítico grecolatino ${ }^{7}$-; el alejamiento de la impersonalidad narrativa del naturalismo -dando paso a menudo a la voz memorialista y subjetiva del autor-; el prerrafaelismo en la descripción de ciertos tipos femeninos; o el gusto por la tradición y el ruralismo primitivo, entre otros ${ }^{8}$.

Por otra parte, La aldea perdida conecta también con el matizado anti-industrialismo que arraigaba también por entonces en el seno del catolicismo social español ${ }^{9}$. En este sentido, no hay que olvidar la crisis espiritual que sufre Palacio Valdés en el periodo 1893-1899, que hará que se derrumben algunos de los postulados que había defendido hasta entonces -como el positivismo-, y le llevará -según propias palabras- a una conversión "sincera y absoluta" al cristianismo. En este sentido, pasó a participar de una de las principales preocupaciones de su amigo Maximiliano Arboleya -canónigo de Oviedo-, a saber: el imparable proceso de secularización social que parecía acompañar al avance de la industrialización, de forma que sólo en el ámbito rural-agrario se mantenía

\footnotetext{
${ }^{6}$ Ramos Gorostiza y Martínez Vara (2011: 282).

${ }^{7}$ En la novela se retrata a los rústicos campesinos como héroes homéricos y se otorgan nombres de dioses clásicos a algunos aldeanos.

${ }^{8}$ Para situar La aldea perdida dentro de la evolución de la novela a finales del siglo XIX y principios del XX, Romero (2003).

9 Sobre el anti-industrialismo en el seno del catolicismo social español véase el artículo de Martínez Vara y Ramos Gorostiza (2012). El principal estudioso del catolicismo social en España y de su relación con el pensamiento socioeconómico es Feliciano Montero: véanse, por ejemplo, Montero (1983), Montero (2001a) y Montero (2001b). También pueden consultarse trabajos como los de Benavides (1973), Sanz de Diego (1979), Cuesta Bustillo (1984) o Perfecto García (2005). Sobre las ideas económicas en el catolicismo social europeo, Almodovar y Teixeira (2008). Entre los autores más significativos del primer catolicismo social español desde el punto de vista socioeconómico estarían, por ejemplo, Rodríguez Cepeda (1887 y 1891) y Valle Ameno (1904).
} 
plenamente la influencia o presencia social de la Iglesia ${ }^{10}$. Pero, sin duda, también era consciente de los otros dos problemas asociados al industrialismo que preocupaban seriamente a la Iglesia católica a comienzos del siglo XX. Por un lado, los continuos conflictos laborales y las crecientes tensiones sociales que marcaban el mundo industrial (y que el catolicismo social español intentaría encarar con la propuesta de vuelta al gremialismo y a un ideal de sociedad orgánico-corporativa). Por otro lado, los males asociados a la "gran industria" y la ciudad industrial, que era vista como un espacio degradado e inmoral, en el que el trabajador venido del campo era víctima del aislamiento, el desarraigo, la deshumanización, la pérdida de referencias, la pugna continua, y los conflictos nacidos de la pobreza y la desigualdad asociadas al capitalismo moderno (tal visión daba lugar a un posicionamiento claramente agrarista y a distintas propuestas para intentar contener la sangría del éxodo rural, y asimismo se combinaba con una actitud abiertamente contraria a la competencia ${ }^{11}$ ).

Lo relevante aquí, en cualquier caso, es que -como se verá en el siguiente apartado- en la novela de Palacio Valdés encontramos, explícita o implícitamente, un buen muestrario de los tópicos anti-industrialistas más habituales en el clima intelectual del cambio de siglo. Por ejemplo: la sombría fealdad estética del paisaje minero-industrial; la crítica a un mundo materialista y utilitario regido por el dinero, convertido en único nexo entre los seres humanos bajo una ética de la codicia y una lógica meramente cuantitativa; la inmoralidad del mercado y la "ley del más fuerte" consagrada por el laissez-faire; el embrutecimiento y la degradación moral de los trabajadores industriales, rebajados a la categoría de máquinas especializadas que habían perdido toda capacidad creativa y eran esclavos de alienantes empleos mecánicos; la añoranza de un universo orgánico y espiritual, destruido por otro mecánico, estandarizado y deshumanizado; la crítica a la gran ciudad por su pérdida del sentido comunitario, su desconexión del entorno natural y su falsedad y miseria moral; la ruptura de la armonía Hombre-Naturaleza, con la destrucción sistemática de esta última; el cuestionamiento de la idea de progreso y de un mundo de abundancia material, creciente sofisticación técnica y alta productividad del trabajo, que sin embargo no conducía a una vida personal más plena y satisfactoria, sino a un mundo de servidumbres laborales y necesidades creadas; o la condena del enconado conflicto social que germinaba en paralelo al avance industrial, y que

${ }^{10}$ Sobre esta cuestión véanse los textos Arboleya (1934) y Arboleya (1936); también González López (2003). Para una visión de Arboleya como teórico del catolicismo social español, véase Arboleya (1901). Una buena síntesis de la opinión del catolicismo social sobre el nuevo mundo industrial en Llovera (1909).

${ }^{11}$ Sobre el discurso anti-competencia del catolicismo social véase Fraile (1998: 149-191). La preocupación del catolicismo social por el éxodo rural, el intento de intentar frenarlo y las posiciones agraristas pueden apreciarse en textos tales como Brañas (1899), Gil Robles (1904), Rubio Coloma (1916) o Cuesta (1921). 
iba acompañado del total abandono de valores tradicionales y creencias religiosas.

\section{LOS MOTIVOS ANTI-INDUSTRIALISTAS EN $L A A L D E A$ PERDIDA}

“'Sí, yo también nací y viví en Arcadia! También supe lo que era caminar en la santa inocencia del corazón entre arboledas umbrías, bañarme en los arroyos cristalinos, hollar con mis pies una alfombra siempre verde. [...] Todo en la tierra era reposo; en el aire, todo amor. Al llegar a la aldea, mi padre me recibía con un beso. El fuego chisporroteaba alegremente; la cena humeaba; una vieja servidora narraba después la historia de alguna doncella encantada, y yo quedaba dulcemente dormido sobre el regazo de mi madre.

La Arcadia ya no existe. Huyó la dicha y la inocencia de aquel valle. ¡Tan lejano! ;Tan escondido rinconcito mio! $Y$, sin embargo, te vieron algunos hombres sedientos de riqueza. Armados de piqueta cayeron sobre ti y desgarraron tu seno virginal y profanaron tu belleza inmaculada" ${ }^{\prime 2}$.

Con estas palabras lapidarias -que aún se conservan grabadas en la voz del propio autor ${ }^{13}$ - comienza La aldea perdida. En ellas se sintetiza en buena medida lo que va a ser la tesis que subyace en la novela: la destrucción de una naturaleza privilegiada y de un modo de vida ancestral, de placeres básicos y sencillos, en nombre del progreso y la civilización que supuestamente acompañan a la industrialización, la cual a su vez avanza inapelable cabalgando a lomos del dinero. Es por tanto el lamento por un paraíso perdido, un idílico mundo rural que parece resultar absolutamente irreconciliable con las nuevas actividades mineras.

El libro nos cuenta las historias de amor de Demetria y Nolo de un lado, y de Flora y Jacinto de otro, que se desarrollan entre tareas del campo y romerías, en un entorno alegre y apacible que sólo se ve levemente alterado por las rivalidades y peleas intrascendentes de los mozos de las poblaciones vecinas. Pero -pese a la enérgica oposición del terrateniente don Félix y del erudito don César- acaban llegando al valle la minería y los mineros, y con ellos aparecen los problemas y los conflictos. No obstante, ya terminando el relato, se van celebrar las bodas de Demetria y Nolo y de Flora y Jacinto, y parece que al cabo todo va a resolverse felizmente; pero justo entonces, camino de la iglesia, estalla una feroz reyerta entre mineros y aldeanos que termina con la dramática muerte de Demetria y Jacinto. Y don César sentencia, proféticamente, cerrando la novela: "Decís que ahora comienza la civilización... Pues bien, yo os digo..., ¡oídlo bien!..., ¡yo os digo que ahora comienza la barbarie!..."

\footnotetext{
${ }^{12}$ Palacio Valdés (2003[1903]: 51).

${ }^{13}$ Véase la página web http://www.palaciovaldes.com/suVoz.php

${ }^{14}$ Palacio Valdés (2003[1903]: 354).
} 
En La aldea perdida se contraponen claramente dos discursos -a favor y en contra de la industrialización-, mantenidos por personajes que remiten a tipos sociales muy concretos. El discurso pro-industrializador aparece en boca del joven liberal Antero -sobrino del capitán don Félix- y de un ingeniero de la compañía minera, aunque entre las voces modernizadoras están también las "fuerzas vivas" de la zona: el farmacéutico, el médico, el alcalde de la Pola, el notario, el recaudador, o el personal administrativo de la empresa minera y su químico belga. Todos ellos, orgullosos y satisfechos de su triunfo, irán luego en plataforma engalanada del tren inaugural cuando, finalmente, vencida ya la tenaz resistencia de los paisanos, se abra la línea del ferrocarril minero ${ }^{15}$.

Antero, "apóstol elocuente del progreso", "abierto a la influencia de las maravillas industriales", es descrito como prototipo de joven liberal español, "versado en economía política", un perfil que quizá se acercase al del propio Palacio Valdés en sus años de juventud ${ }^{16}$. Antero alude al bienestar que llegará a Entralgo con el carbón, auténtico "oro negro" que traerá comodidades y suculentos jornales a las casas, dejando atrás la mera subsistencia y permitiendo atender nuevas necesidades creadas, propias de una vida variada y plena:

"Amaneció al cabo el día por nosotros tan ansiado, el día que nuestro valle salga de su profundo y secular letargo. Aquellos tesoros que nuestros padres pisaron siglos y siglos sin sospechar su existencia, para nosotros los amontonó la naturaleza debajo del suelo; para nosotros y para nuestros hijos. Los desgraciados habitantes de esta región, que apenas pueden, a costa de grandes esfuerzos, llevar un pedazo de borona a la boca, dentro de pocos días, gracias a la iniciativa de una poderosa casa francesa que va a sembrar aqui sus capitales, encontrarán medios de emplear sus fuerzas, ganarán jornales jamás soñados por ellos. Y con estos jornales se proporcionarán muy pronto las comodidades y los goces que embellecen la vida. Porque el hombre no está destinado a vegetar como un hongo tomando de la tierra lo estrictamente necesario para no fenecer de hambre; tiene otras necesidades. Dentro de nuestro corazón existe un impulso que nos hace apetecer nuevos y variados elementos de vida, cambios incesantes que nos ofrezcan formas más y más interesantes de existencia [...]. Para que el hombre se eleve, para que exista el progreso, es necesario que prescin-

\footnotetext{
${ }^{15}$ Sobre el modo de dibujar la figura de los ingenieros y el ideal de progreso en la literatura española decimonónica, Ordóñez (2007) y Ara Torralba (2007).

${ }^{16}$ Palacio Valdés (2003[1903]: 129). El escritor asturiano estudió la carrera de Derecho en Madrid desde 1870, donde frecuentó a su paisano Leopoldo Alas; allí se licenció en 1874 y llegó a dar clases de Economía Política durante algunos meses en la Escuela de Estudios Mercantiles de San Isidro. En esta etapa inicial el escritor comulgó con los principios liberales y también tomó contacto con el pensamiento krausista; por entonces se mostraba anticlerical, amante de la libertad y del progreso técnico, y seguidor incondicional del racionalismo científico (Ruiz de la Peña, 2003: 15). Sobre la vida y la ideología de Palacio Valdés véase Gómez-Ferrer (2005: 140-147), quien también estudia cómo reflejó en sus obras el escritor asturiano la realidad sociopolítica de su época.
} 
damos de ese respeto exagerado a la costumbre, que no temamos crearnos necesidades. Las necesidades son acicates que sacuden nuestra indolencia. Es necesario que nos relacionemos con los paises extranjeros para hacernos participes de sus adelantos [...] Dentro de pocos meses oiréis resonar por estas montañas el agudo silbido de la locomotora. Es la voz del vapor que nos llama a la civilización" "17.

Como se aprecia en el extenso fragmento anterior, Antero es un firme creyente en la idea de progreso, que a mediados del siglo XIX era ampliamente compartida como auténtico motor de la humanidad, y que incluso a principios del siglo XX, cuando Palacio Valdés escribe la novela -poco antes de la Gran Guerra-, aún mantenía en gran medida su atractivo ${ }^{18}$. Normalmente, esa fe en el progreso -que compartían liberales, socialistas y anarquistas- iba de la mano de una inquebrantable creencia en la bondad de los avances científicos y técnicos, y daba lugar a exaltados cantos a los espectaculares adelantos tecnológicos y a su capacidad para influir favorablemente en las condiciones de vida humana ${ }^{19}$. En esta línea precisamente se sitúa Antero, para quien -por tanto- el cambio se impone: "el amor y el respeto por el pasado" no debe arrastrar a nadie "a privar a este valle de lo que tiene derecho a alcanzar: mayor bienestar para sus hijos y un puesto en la civilización"20.

Por su parte, el posicionamiento del ingeniero de la Unión Carbonera -empresa de capital francés radicada en Gijón ${ }^{21}$ - es aún más radical, llegando a equiparar la tradicional alimentación a base de borona o pan de maíz -que él sólo considera apto para las bestias- con la torpeza y el retraso intelectual:

"Con qué profunda tristeza he visto a los pobres labradores alimentarse con ese pan miserable. Entonces he comprendido la razón de su atraso intelectual, la lentitud de su marcha, la torpeza de sus movimientos, la rudeza de todo su ser. Quien introduce en su estómago diariamente un par de libras de borona, no es posible que tenga la imaginación despierta y el corazón brioso. Procuremos [...] que pronto se sustituya por el blanco pan del trigo. Con él, no lo dudéis, despertará la inteligencia, se aguzará el ingenio, crecerán los ánimos y, por fin, entrarán en el concierto de los hombres civilizados los habitantes de este país $^{, 22}$.

${ }^{17}$ Palacio Valdés (2003[1903]: 136-137).

${ }^{18}$ Pollard (1971) y Bury (1971).

${ }^{19}$ Véanse, por ejemplo, Petrel O’Sullivan (2009) y Martykánová (2007) sobre la visión del progreso en los ingenieros y las clases industriales. Para ilustrar la exaltación del progreso técnico y mecánico en el caso del anarquismo español -que enfatizó Álvarez Junco (1976)- valga por ejemplo el revelador texto de Lluria (1933[1906]).

${ }^{20}$ Palacio Valdés (2003[1903]: 140).

${ }^{21}$ La presencia de empresas y técnicos franceses en los inicios de la industrialización asturiana, desde la década de 1840, fue efectivamente relevante.

${ }^{22}$ Palacio Valdés (2003[1903]: 137-138). 
En contraste con los planteamientos de Antero y del ingeniero, el discurso anti-industrialista, de mucho mayor peso relativo en La aldea perdida, lo desarrollan fundamentalmente dos personajes también muy característicos: el terrateniente y capitán retirado don Félix, y su primo, el erudito amante del mundo clásico don César de las Matas de Arbín. De los dos, don Félix es quien plantea los argumentos más pragmáticos. En primer lugar, ¿por qué pretender otros medios de vida si ya disfrutan de una buena provisión de maíz, judías, patatas, legumbres, leche, manteca, carne, castañas, avellanas y frutas? ¿No habían vivido hasta entonces "sin necesidad de hurgar en la tierra como topos"?: "Hasta ahora hemos vivido a gusto en este valle sin minas, sin humo de chimeneas ni estruendo de maquinaria. [...] [Por tanto,] ¿para qué buscar debajo de la tierra lo que encima de ella nos concede la providencia, alimento, vestido, aire puro, luz y leña para cocer nuestro pote y calentarnos en los días rigurosos del invierno?" 23 .

En segundo lugar, don Félix llama la atención de los campesinos sobre lo penoso y expuesto del trabajo minero con objeto de que no se dejen tentar por el dinero fácil que promete la propaganda industrialista. Se trata de una actividad que "no es propia de hombres libres":

"Cada peseta que aquí dejen os costará bastantes gotas de sudor. Y entre sudar debajo de la tierra o a la luz del sol, es preferible esto último. [...] [Los que trabajan en el campo] están seguros de que no les cae encima la montaña y les entierra como hormigas, y de que el aire no se encenderá para quemarles la cara y las manos. No serán solamente gotas de sudor lo que derramaréis dentro de poco, sino lágrimas, lágrimas bien amargas. ;Dichosos los que tranquilamente reposan de su trabajo a la fresca sombra de un árbol y comen un pedazo de borona con alegría!"24.

Y por si todo esto no fuera suficientemente convincente, alude a la experiencia palpable de lo ya sucedido en Langreo ${ }^{25}$, con el fin de poner en duda que la supuesta prosperidad asociada al carbón fuera a llevar al valle dicha alguna. Es cierto que, aparentemente, los de la industria minera "traen muy bien repleta la bolsa", y sin duda hay en la zona "muchos infelices a quienes [el dinero] les vendrá muy bien"; sin embargo,

"los hombres trabajarán más que antes y no a la luz del día y respirando la gracia de Dios como ahora, sino metidos en negros, inmundos agujeros. Las mujeres lavarán más ropa sucia, cuidarán más enfermos, quedarán viudas primero.

${ }^{23}$ Palacio Valdés (2003[1903]: 114).

${ }^{24}$ Palacio Valdés (2003[1903]: 117). En un momento dado, el reflexivo tabernero Martinán abunda en esta misma dirección: "Te digo que [las minas] acaso sean nuestra desgracia [...] Tú bien sabes que en las minas se matan algunas veces los hombres..., ¿no me lo negarás?... [....] Pues bien, por la muerte de un hombre se pierde una familia" (p. 161).

${ }^{25}$ La primera línea ferroviaria asturiana, construida entre 1851 y 1854, surgió para transportar el carbón desde el concejo de Langreo hasta el puerto de Gijón. 
Yo me río de esa prosperidad y la maldigo. ¿Qué me importa que traigáis un puñado más de oro, si con él llega el vicio, el crimen y la enfermedad?"26.

Por su parte, don César aporta los argumentos más filosóficos. Apela a la vieja oposición campo-ciudad, la tradición bucólica que ya estaba presente en la Antigüedad grecolatina y que enfrentaba la simplicidad de costumbres y la pureza moral del campo con la corrupción y ansiedades propias de la urbe, y que luego, ya en la Ilustración, se vinculará al tema del buen salvaje, contraponiendo el bárbaro-bondadoso, que vive en armonía con su medio disfrutando de las virtudes, el sosiego y los prosaicos goces de la vida campestre, al civilizadocorrompido $^{27}$. Don César, pues, alertaba a sus paisanos contra el "tráfago y estruendo de las ciudades", con su "boato" y "etiqueta", sus caprichosas y cambiantes modas, sus corrompidas costumbres y su humanidad degradada ${ }^{28}$ :

“;Ay de los pueblos que corren presurosos en busca de novedades! ;Ay de los que, olvidando las prístinas y sencillas costumbres de sus mayores, se entregan a la molicie! [...] El régimen austero, la vida sobria y sencilla [...] desaparecerá muy presto. Los productos refinados de la industria, las modas y los deleites corromperán nuestras costumbres, debilitarán luego nuestros cuerpos y no quedarán al cabo más que hombres afeminados y corrompidos, miserables sofistas, despreciables parásitos que escucharán temblando el chasquido del látigo romano,"29.

Y luego, con ironía, animaba a valorar las maravillas de la naturaleza que aún se conservaban en el valle, dones en los que nadie reparaba y que todo el mundo daba por supuestos por haber disfrutado de ellos gratuitamente durante generaciones: "¿Qué valen nuestros tupidos castañares, ni tus rebaños lucidos, ni este aire puro de la montaña, ni esta luz radiosa que el cielo nos envía delante de esas altas chimeneas que tiñen de negro sin cesar la tierra y el firmamento?" 30 .

Los mineros, de "rostros macilentos" y "miradas insolentes y provocativas", que además "parecían sentir profundo desprecio por aquellos aldeanos y sus juegos", son presentados en la novela como arquetipos de todos los vicios y defectos de la civilización urbano-industrial, en claro contraste con los sencillos, inocentes y honestos campesinos, que aún profesaban una fe sincera en los

\footnotetext{
${ }^{26}$ Palacio Valdés (2003[1903]: 140).

${ }^{27}$ Como ha mostrado Dietz (2008), la oposición campo-ciudad seguía aún muy presente en determinadas corrientes del pensamiento de comienzos del siglo XX en países como Alemania o Reino Unido. Para las críticas a la ciudad industrial véase Ramos Gorostiza (2008).

${ }^{28}$ Palacio Valdés (2003[1903]: 119).

${ }^{29}$ Palacio Valdés (2003[1903]: 115).

${ }^{30}$ Palacio Valdés (2003[1903]: 115).
} 
principios cristianos ${ }^{31}$. En particular, Palacio Valdés se ceba especialmente en la descripción de los dos malos del relato, los mineros Joyana y Plutón, "fieras traidoras" de "mirada dura" y "agresiva", cuya "estructura de mono" denotaba "bastante agilidad y fuerza" 32 . El problema era que, finalmente, los mineros, esos representantes del descreído mundo industrial, acabarían contaminando -y eventualmente destruyendo- las sanas y ancestrales costumbres campesinas y su cultura, en cuyo trazo se recrea el escritor a lo largo de toda la novela (los bailes, las fiestas populares y las romerías, los juegos y las tradiciones, los pastores y sus ganados, las labores del campo y los quehaceres del hogar, las indumentarias y los usos culinarios, la devoción cristiana y los oficios religiosos, los trabajos artesanos y las construcciones rústicas tradicionales, los paisajes agrarios, etc. ${ }^{33}$ ). Y es que, en efecto, en la medida en que muchos padres empezaron a enviar a sus hijos a la mina buscando la entrada en sus pobres casas labriegas de "un chorro no despreciable de dinero", pronto "los mineros enseñaron a los zagales sus vicios. Aquellos mozos, antes tan parcos y sumisos, se tornaron en pocos meses díscolos, derrochadores y blasfemos. No solamente cambiaron su pintoresco traje aldeano por el pantalón largo y la boina, sino que se proveyeron casi todos [...] de navaja y revólver", frecuentando a todas horas las tabernas, alborotando con "cánticos desacordados, disputas y blasfemias", y haciendo habituales "los tiros y las puñaladas" en aquel valle otrora tranquilo y atrasado $^{34}$.

En definitiva, poco a poco los paisanos en general, aunque algo recelosos al principio, se fueron mostrando satisfechos de las nuevas posibilidades de ingresos: el "viento de la ambición" se había levantado, y -pese a los reparos de la mayoría de las mujeres- "apenas quedaba un individuo del sexo masculino que no se hallase excitado por la idea de enriquecerse". Al fin y al cabo, "puesto que debajo de los pies tenían el dinero necesario para procurarse algunas comodidades, ¿por qué no recogerlo?". Esto es, sólo se trataba de "beneficiar lo que Dios había puesto debajo de la tierra", y -bien pensado- "pasar toda la vida con borona, leche y judías era bien duro". Así que, por un lado, quien más quien menos esperaba tomar algún dinero extra, aunque fuera "de los jornales de sus hijos, pues se aseguraba que admitían en la mina hasta los niños de diez años" (quienes, a su vez, "hasta preferían esto a la escuela, orgullosos de la precoz independencia que su calidad de obreros les proporcionaba") ${ }^{35}$. Y por otro lado,

\footnotetext{
${ }^{31}$ Palacio Valdés (2003[1903]: 144). Sobre la actividad minera en la literatura y en la novela de Palacio Valdés véase Delmiro (1993 y 2003).

32 Palacio Valdés (2003[1903]: 177; 148).

${ }^{33}$ Véase, por ejemplo, Palacio Valdés (2003[1903]: 251-253; 265-266). Sobre el reflejo de la Asturias tradicional en La aldea perdida, Trinidad (2005).

${ }^{34}$ Palacio Valdés (2003[1903]: 276).

${ }^{35}$ Palacio Valdés (2003[1903]:159-160).
} 
el dinero fluía gracias a "las cuadrillas de mineros y operarios traídas de otros puntos, [que] se alojaban en casa de los labradores [...] y dejaban allí parte de su salario", compensando así el hecho de aguantar su carácter pendenciero y alborotador $^{36}$. En cualquier caso, el vil metal iba socavando unas relaciones interpersonales antes cooperativas, basadas en la ayuda mutua y la palabra dada.

De este modo, llegó un momento en que el cambio se consideró ya inevitable: "todos sentían que una transformación inmensa, completa, se iba a operar pronto en Laviana. El mundo antiguo, un mundo silencioso y patriarcal que había durado miles de años, iba a terminar, y otro mundo, un mundo nuevo, ruidoso, industrial y traficante, se posesionaría de aquellas verdes praderas y de aquellas altas montañas" ${ }^{37}$. Hasta el propio don Félix -que se había resistido con todas sus fuerzas- llegó a ser consciente de que en último término no le quedaría más remedio que aceptar el dinero de la expropiación forzosa para que el ferrocarril minero atravesase sus tierras ${ }^{38}$, e incluso -finalmente- intentaría sacar partido de la nueva situación ${ }^{39}$.

En paralelo, paulatinamente, la Naturaleza iba siendo "profanada", el bucólico paisaje desparecía sin remedio, y el hombre iba imponiendo su dominio sobre un medio con el que hasta entonces había convivido en armonía, contaminando y destruyendo. La Belleza dejaba paso a la Utilidad: "El valle de Laviana se transformaba. Bocas de minas que fluían la codiciada hulla, manchando de negro los prados vecinos; alambres, terraplenes, vagonetas, lavaderos: el río, corriendo agua sucia; los castañares, talados; fraguas que vomitaban mucho humo espeso esperando que pronto las sustituirían grandes fábricas que vomitarían humo más espeso todavía". En suma, un nuevo entorno, hecho a la medida del hombre moderno, iba tomando forma. Como decía satisfecho el joven Antero en una de sus cartas al Eco de Asturias: "El sol de la industria ilumina ya este valle, antes tan oscuro, y esparce sus rayos vivificantes sobre

\footnotetext{
${ }^{36}$ Palacio Valdés (2003[1903]: 276).

${ }^{37}$ Palacio Valdés (2003[1903]: 158).

${ }^{38} \mathrm{Al}$ menos, "un puñado de oro iba a caer en sus manos. Lo agrio con lo dulce" (Palacio Valdés, 2003[1903]: 180).

${ }^{39}$ Poco antes de terminar la novela, en la celebración festiva previa a las bodas, la resignación de don Félix -que tan radicalmente se había opuesto a las minas y al ferrocarril- es ya total: ante la evidencia palmaria de la inevitabilidad del progreso industrial, pretenderá al menos aprovecharse -él también- de los nuevos tiempos. Es decir, el dinero y el mundo de los negocios habían triunfado por completo, doblegando incluso al numantino Don Félix. "Monsieur, tienen ustedes razón; hay que extraer la riqueza que se halla oculta en este valle. Yo no la necesito ya, pero pronto he de tener nietos y quiero dejarlos bien acomodados. Cuenten ustedes con mi dinero para cualquier empresa lucrativa" (Palacio Valdés, 2003[1903]: 350). Pero ya nadie le tomará en serio, achacando sus palabras al efecto del vino.
} 
estos pobres campesinos subviniendo a sus necesidades, llevando a su frío hogar el alimento y el bienestar"

Pero progreso industrial y el aumento del bienestar material no iban necesariamente de la mano de la civilización y la mayor felicidad colectiva, y el abuso de la madre Naturaleza también podía acabar pasando factura. Así lo entendía don César, que, en medio de la sarcástica burla de muchos de sus convecinos, afirmaba con convicción:

"Ignoro [...] si esos que llamáis progresos industriales van tan estrechamente unidos a la causa de la civilización como os complacéis en suponer. El genio del hombre, excitado por la necesidad e irritado por los obstáculos, se arroja a la conquista de la tierra y descubriendo sus secretos los utiliza para su alivio. Mas con frecuencia [...] va más allá de lo que le dicta la santa naturaleza. [...] Lo que se nos ha dado como un medio lo convertimos en fin. De aqui se origina siempre un grave desequilibrio, que engendra la corrupción y los vicios. Entonces la sabia naturaleza, que vela por los destinos del hombre, dice: ;basta! Y las naciones corrompidas degeneran y se extinguen y las ciudades opulentas desaparecen. [...] Todo con medida, nos repite sin cesar el universo que habitamos. El exceso se paga más tarde o más temprano. [...]. Temo [...] que confundáis lamentablemente la civilización con el industrialismo. Yo sé de paises muy industriales donde la cultura del espíritu no corre parejas con las comodidades y refinamientos de la vida. [...] ;Todo vulgar, todo abatido, todo triste!",4l.

No obstante, finalmente la industrialización minera se impuso por completo en el concejo de Laviana. La señal definitiva de que tal cosa había sucedido fue que en todo el valle se oían ya "los pitos de esas endiabladas máquinas que llaman locomotoras", triunfantes, "abriendo enorme brecha en los castañares que lo señorean", "taladrando con furia" los prados, "vomitando humo y escorias" $"$. Don Félix veía por fin completamente destruidas sus antes bellas tierras, en el que fue uno de los días más tristes de su vida:

"El hermoso, florido campo que tanto amaba habia sido partido, destrozado. Una trinchera bien ancha separaba las dos mitades; por medio de la trinchera cruzaba la vía férrea. El encanto silencioso, la dulzura agreste, la amable soledad de aquel retiro habian desaparecido [...] Apoyándose en su bastón, miraba con terrible insistencia aquella brecha que la piqueta del progreso había abierto en su campo [...] Dentro de poco tiempo no [quedaría] en este valle ningún sitio sin agujerear,"

Entretanto, los trenes cargados de mineral, emblema de los nuevos tiempos,

\footnotetext{
${ }^{40}$ Palacio Valdés (2003[1903]: 276).

${ }^{41}$ Palacio Valdés (2003[1903]: 289-290).

${ }^{42}$ Palacio Valdés (2003[1903]: 116; 285). La peculiar presencia de los trenes en la literatura española de la segunda mitad del siglo XIX y principios del XX ha sido estudiada por Litvak (1991), González Herrán (1996) y Ponce (1996).

${ }^{43}$ Palacio Valdés (2003[1903]: 293; 322).
} 
surcaban ya con regularidad las praderías, pero sin conseguir aún hacerse un elemento habitual en el paisaje, despertando todavía una especie de disconformidad en el entorno: los "penetrantes silbos estremecían la campiña. Volaban los pájaros, corrían las reses hasta despeñarse, huían los niños, ladraban los perros en los caseríos, jcomo si en vez del bienestar y la riqueza les trajese aquel glorioso artefacto la oscuridad, la maldición y la guerra!" 44 . Y don César, por su parte, con un tono retórico y grandilocuente, aceptaba la derrota y levantaba acta de defunción definitiva del mundo agrícola, base de la vida social y la economía durante siglos, y que ahora desaparecía, en pocos años, llevándose con él sus muchas virtudes ${ }^{45}$ :

"La gloriosa Demetria, la diosa de la agricultura, la diosa que alimenta [...] ha muerto y se prepara el advenimiento de un nuevo reinado: el reinado de Plutón. Saludémosle con respeto, ya que no con amor... ¡Con amor, no! Yo no puedo amar a ese dios subterráneo que ennegrece los rostros y no pocas veces también las conciencias. La Arcadia ha concluido. Esta raza sencilla y belicosa de nuestros campos desaparecerá en breve y será sustituida por otra criada en el amor de las riquezas y en el orgullo. [...] A la aristocracia sucede la plutocracia ${ }^{46}$.

\section{EL COMPONENTE ANTI-INDUSTRIAL EN LA ADAPTACIÓN CINEMATOGRÁFICA}

El melodrama "La aguas bajan negras" (102 min.) es una adaptación de La aldea perdida (1903) rodada en 1948. Dirigida con oficio por José Luis Sáenz de Heredia (1911-1992), con guión de Carlos Blanco y una buena fotografía de Alfredo Fraile, cuenta en el reparto al italiano Adriano Rimoldi como actor principal, secundado por Charito Navarro, Tomás Blanco, José María Lado, Mary Delgado y Raúl Cancio. Parece que Sáenz de Heredia se vio influido por el neorrealismo que entonces triunfaba en Italia, aunque en realidad la película no puede encuadrarse estrictamente en esta estética. Por lo que respecta a su valoración, el conjunto no llega a cuajar por completo, si bien hay algunos momentos bastante logrados, con fuerza visual. Y en lo referente al porqué de la elección de la novela de Palacio Valdés para su adaptación cinematográfica, cabe señalar que se trataba de un texto que no desentonaba con las coordenadas ideológicas del momento y que pertenecía a un autor célebre fuera de toda sospecha, que había muerto olvidado en plena Guerra Civil tras malvivir aislado y

\footnotetext{
${ }^{44}$ Palacio Valdés (2003[1903]: 285).

${ }^{45}$ Sobre el reflejo de la organización agraria tradicional en la obra de Palacio Valdés, Rodríguez Felgueroso (2005).

${ }^{46}$ Palacio Valdés (2003[1903]: 205).
} 
pasando graves penurias en el Madrid republicano. De hecho, fueron bastantes las novelas de Palacio Valdés llevadas al cine durante el franquismo ${ }^{47}$.

Sáenz de Heredia, primo de José Antonio Primo de Rivera, había comenzado su carrera en la II República, demostrando ya aptitudes bajo los auspicios de Luis Buñuel, que entonces era responsable de producción de los estudios Filmófono, fundados por el empresario vasco Ricardo de Urgoiti. Pero con la llegada del franquismo se convertiría en el cineasta oficial del régimen, rodando "Raza" (1942) -con argumento del propio Franco- y el documental hagiográfico "Franco, ese hombre" (1964). En cualquier caso, Sáenz de Heredia fue también probablemente, de facto, el director más destacado del cine español de los años cuarenta y cincuenta, filmando algunos de los trabajos más interesantes de la época, que además alcanzaron un éxito de público notable, tales como "El escándalo" (1943), "El destino se disculpa" (1945) o "Historias de la radio" (1955).

José Antonio Primo de Rivera estaba interesado en una transformación de las relaciones campo-ciudad, y para ello planteaba una serie de medidas intervencionistas de carácter general ${ }^{48}$. Así, la oposición entre lo rural y lo urbano constituía ya un elemento clave de la ideología falangista en los años treinta ${ }^{49}$, algo que -como se ha señalado anteriormente- estaba también presente en el corporativismo católico de finales del siglo XIX. Pues bien, en la inmediata postguerra, la Doctrina Social de la Iglesia se convertiría, de forma explícita y junto al ideario falangista, en una de las principales inspiraciones del primer franquismo. Por eso, aunque en la práctica el régimen apostara decididamente por la industrialización, durante los años autárquicos de la década de los cuarenta -e incluso hasta mediados de la década de los cincuenta- dominó formalmente, en discursos y escritos de todo tipo, una retórica oficial agrarista de firme defensa del campo, con llamamientos a una "vuelta a la tierra" e idealiza-

${ }^{47}$ Santa Rogelia, coproducida con Italia en 1939, La fe en 1947, Las aguas bajan negras en 1947, Tiempos felices en 1949, El señorito Octavio en 1950, Bajo el cielo de Asturias (inspirada en Sinfonía Pastoral) en 1950, de nuevo La hermana San Sulpicio en 1952, y otra vez Rogelia en 1963. En Argentina se produjo, en 1946, La maja de los cantares, sobre la obra Los majos de Cádiz (Piñera, 2005: 253).

${ }^{48}$ Por ejemplo, un precio mínimo garantizado para los productos agrarios, la mejora general de la tierra de cultivo a través del riego, la mejora de la educación sobre cuestiones agrícolas, el fomento del crédito agrario, la restitución de las tierras comunales, la racionalización de la tenencia de la tierra -con la eliminación de aquellos latifundios que fueran ineficientes y la concentración parcelas excesivamente pequeñas-, etc. (Bramwell, 1989: 163).

${ }^{49}$ Antes incluso de la Guerra Civil, véanse las explícitas citas que sobre esta cuestión recoge Velasco (1982: 239-245), tomadas de publicaciones falangistas de los años treinta como Arriba o F.E. 
ciones de la vida campesina en la naturaleza frente a las miserias de la ciudad industrial ${ }^{50}$.

Enlazando con dicho planteamiento retórico, el falangista Nieves Conde lanzaría a comienzos de los cincuenta un mensaje claramente anti-industrialista y anti-urbano en "Surcos" (1951), denunciando el éxodo rural ${ }^{51}$. Sin embargo, el también falangista Sáenz de Heredia mantendría un discurso mucho más matizado y neutro en "Las aguas bajan negras" (1948), pese a basar su película en la novela abiertamente anti-industrialista de Palacio Valdés. De hecho, como se intentará mostrar a continuación, en el largometraje este aspecto quedó en gran medida relegado y desdibujado por ciertos adornos y licencias del guión respecto al texto original.

La película se centra sólo en la historia de amor de Carmina -Demetria en la novela- y Nolo (no aparece por tanto la otra pareja, Flora-Jacinto). Comienza remontándose a la primera guerra carlista, para mostrar el romance entre una dama de alta cuna y un oficial carlista en 1839, y luego da un salto temporal a Rubiercos -Entralgo-, hacia la década de 1860, para iniciar propiamente la historia; al final descubrimos que Carmina fue dejada al cuidado de dos aldeanos pudientes, el tío Goro y la tía Felicia, y que su verdadera madre -la dama del comienzo- regresa de su exilio cubano para reencontrarse felizmente con ella. Sin embargo, en el libro de Palacio Valdés no hay nada de los antecedentes carlistas que recoge el film y la historia "secreta" de Demetria tiene menos relevancia y es mucho menos amable: es llevada a la fuerza a la hostil ciudad por su verdadera madre -de la que desconocemos su pasado- y recluida en un internado, de donde huirá con ayuda de Nolo para volver con los que ella considera sus padres, el tío Goro y la tía Felicia.

Por otra parte, en la película no se produce el choque frontal entre el mundo tradicional agrícola y el nuevo mundo industrial y minero (que en el libro se muestran como completamente irreconciliables), ni la crítica feroz al "progreso" industrial, ni la carga absolutamente negativa que tienen en el libro los mineros como grupo. Todo está muy suavizado y dulcificado respecto a la novela. Así, en "Las aguas bajan negras" el propio protagonista -Nolo- decide trabajar voluntariamente en la mina para obtener mayores ingresos, rompiendo así con los recelos de los que se resisten al cambio, representados por el tío Goro (un personaje que en el libro es secundario y no forma parte de la reacción anti-minera, mientras que en el largometraje hace la labor de oposición de don Félix y don César, que no aparecen en la cinta cinematográfica). Además, el cura don Prisco desempeña un papel mucho más destacado que en la novela por su influencia en

\footnotetext{
${ }^{50}$ Sobre la retórica agrarista del primer franquismo, a través de numerosas y reveladoras citas, véase Velasco (1982).

${ }^{51}$ Silvestre y Serrano (2011).
} 
la comunidad campesina, y en un momento dado empieza a mostrarse proclive al avance de la industria minera ${ }^{52}$. La película también se separa de la línea de la narración de Palacio Valdés porque Sáenz de Heredia no se recrea en el bucolismo y las buenas costumbres del campo frente a los "males" de la civilización $^{53}$. Y por último, en la película -de final feliz- tampoco se da el dramático enfrentamiento entre mineros y campesinos con el que termina la novela, y en el que mueren dos de los personajes principales.

Es cierto que, inicialmente, cuando en la película llega a Rubiercos el ingeniero de la "Compañía Minera del Norte" y explica a los paisanos sus planes sobre la extracción de carbón -esa "sangre de nuestra época"-, éstos le discuten y se muestran reacios a colaborar ${ }^{54}$. Luego vemos los efectos de la minería en el valle, con las explosiones preparatorias para la apertura de minas y la transformación del paisaje ${ }^{55}$. Y también hay una discusión destacada entre el cura don Prisco y el tío Goro sobre el supuesto progreso asociado a la minería, así como el intento de convencer a este último ${ }^{56}$. Pero el limitado conflicto entre mineros y campesinos sólo se desencadena después de que el minero Plutón, que intenta aprovecharse de Carmina tras haberla atraído al interior de la mina con el engaño de que Nolo había sufrido un accidente, resulta muerto, y el tío Goro es acusado injustamente de haberle asesinado ${ }^{57}$. No obstante, finalmente todo se aclarará y la situación será reconducida.

En definitiva, en la película termina imponiéndose la minería como un paso lógico en la inevitable modernización, que parece aceptarse por fin con naturalidad. Este es el mensaje que nos traslada Sáenz de Heredia, que es muy distinto al de la novela -de firme cuestionamiento de un progreso industrial que causa graves daños morales y destruye cruelmente un idílico mundo rural tradicional-. Al mismo tiempo, el mensaje del film es acorde a lo que realmente pretendía el régimen de Franco por aquellos años: un decidido impulso industrializador entendido como base del avance del país, aunque fuera bajo una fachada de propaganda y retórica agrarista que contentaba a ciertos sectores sociales vinculados a la Iglesia y la Falange.

\section{CONCLUSIÓN}

Como ha señalado Jean-Françoise Botrel (2005), La aldea perdida ha tenido

\footnotetext{
${ }^{52}$ Véanse en la película los minutos 41:05 a 43:22.

${ }^{53}$ No obstante, hay algunas alusiones pasajeras en imágenes al fervor religioso de los campesinos (13:28), a los bailes tradicionales (21:57) y a los bellos paisajes agrarios (15:50).

${ }^{54}$ En la película, 22:23-27:56.

${ }^{55}$ En la película, respectivamente, 27:57-30:30 y 30:30-34:36.

${ }^{56}$ En la película, 43:22-48:08.

${ }^{57}$ Véase en la película 69:18-74:13, y también 76:36-78:07.
} 
múltiples lecturas. Aunque la anti-industrialista es sin duda una de las más evidentes, curiosamente aún no había sido analizada con cierto detenimiento, y esto es precisamente lo que se ha intentado hacer en el presente trabajo. En este sentido, lo interesante de la novela de Palacio Valdés, construida a partir de su propia experiencia personal respecto a la transformación minera del valle de Laviana, es que en ella encontramos un amplio muestrario de los argumentos anti-industrialistas que flotaban en el ambiente en el cambio del siglo XIX al $\mathrm{XX}$, enlazando con la corriente anti-industrialista "fin de siglo" y también con la postura del primer catolicismo social.

Aunque el escritor asturiano partía en su libro de un planteamiento excesivamente naïve que enfrentaba un idealizado mundo rural tradicional al maligno mundo minero, este cuadro en "blanco y negro" resultaba muy eficaz a la hora de poner de manifiesto la crítica a la industrialización. Luego dicho componente crítico quedó muy descafeinado en la adaptación cinematográfica de Sáenz de Heredia, realizada en un momento -el primer franquismo- en el que el agrarismo de la retórica oficial se conjugaba con la orientación abiertamente industrialista de la política económica práctica.

En cualquier caso, podemos insertar La aldea perdida en una tradición crítica muy larga: tendría su antecedente en la vieja oposición campo-ciudad presente desde el mundo clásico, tomaría forma en el anti-industrialismo "fin de siglo" con sus componentes anti-urbano, anti-maquinista y anti-mercado, y conectaría posteriormente con la condena de la civilización industrial de la contracultura de la década de 1960 y los actuales grupos alternativos anticapitalistas, especialmente preocupados por los problemas ambientales.

\section{REFERENCIAS BIBLIOGRÁFICAS}

ALMODOVAR, Antonio, y TEIXEIRA, Pedro (2008): "The Ascent and Decline of Catholic Economic Thought 1830-1850s", History of Political Economy, 40, pp. 62-87.

ÁLVAREZ JUNCO, José (1976): La ideología política del anarquismo español (18681910), Madrid: Siglo XXI.

ARA TORRALBA, Juan Carlos (2007), "Asombros, euforias y recelos: consideraciones acerca de la percepción del progreso técnico en la literatura del siglo XIX", en Silva Suárez, Manuel (ed.), Técnica e Ingeniería en España, IV: El Ochocientos: pensamiento, profesiones y sociedad, Zaragoza: Real Academia de Ingeniería - Institución "Fernando El Católico" - Prensas Universitarias de Zaragoza, pp. 427-465.

ARBOLEYA, Maximiliano (1901): La misión social del clero, Oviedo: Imp. Uría Hermanos. 
ARBOLEYA, Maximiliano (1934): "La apostasía de las masas", en Crisis moral, social y económica del mundo. VII Curso de las Semanas Sociales de España, Madrid, pp. 443-480.

ARBOLEYA, Maximiliano (1936): "Necesidad y procedimientos prácticos de elevar la vida moral y religiosa de la población campesina", en Problemas Agrarios de España. VIII Curso de las Semanas Sociales de España, Zaragoza, pp. 517-549.

BENAVIDES, Domingo (1973): El fracaso social del catolicismo español. Arboleya Martínez (1870-1951), Barcelona: Nova Terra.

BOTREL, Jean-Françoise (2005): "Lectores y lecturas de La aldea perdida", Palacio Valdés en Asturias: actas del II Congreso Internacional Armando Palacio Valdés y su Obra, celebrado en Entralgo (Laviana), los días 4, 5, 6 y 7 de octubre de 2005. Entralgo (Laviana): Centro de Interpretación Armando Palacio Valdés, pp. 13-33.

BRAMWELL, Anne (1989): Ecology in the 20th Century: A History, New Haven: Yale University Press.

BRAÑAS, Alfredo (1899): "Por qué emigran", Revista Católica de Cuestiones Sociales, $\mathrm{n}^{\text {os }} 49,50,51$ y 56 .

BURY, John (1971): La idea de progreso, Madrid: Alianza.

CALVERA, Anna (1997): "Acerca de la influencia de William Morris y el movimiento Arts \& Crafts en Cataluña", D’Art, $n^{\circ} 23$, pp. 231-252.

CARLYLE, Thomas (1971): Selected Writings, editados por Alan Shelston, Hammondsworth: Penguin.

CASAMAYOR, Juan (1998): "Palacio Valdés: el narrador de aventuras galantes", en A. Palacio Valdés, Cuentos de mansos, pícaros y ahorcados, Madrid: Clan, pp. 7-33.

CUESTA, Manuel S. (1929): "La despoblación del campo", Revista Católica de Cuestiones Sociales 411, pp. 138-142.

CUESTA BUSTILLO, Josefina (1984): "Estudios sobre el catolicismo social español (1915-1930): un estado de la cuestión”, Studia Historica. Historia Contemporánea, vol. 2, pp. 193-244.

DELMIRO, Benigno (1993): La voz en el pozo: el trabajo en las minas y su presencia en la literatura, Madrid: Akal.

DELMIRO, Benigno (2003): "La aportación de Palacio Valdés a la literatura minera", Palacio Valdés: un clásico olvidado (1853-2003): actas del I Congreso Internacional Armando Palacio Valdés, celebrado en Entralgo (Laviana) los días 24, 25 y 26 de septiembre de 2003, Entralgo (Laviana): Centro de Interpretación Armando Palacio Valdés, pp. 105-130.

DIETZ, Bernhard (2008): "Countryside-versus-city in European thought: German and British anti-urbanism between the wars", European Legacy, 13 (7), pp. 801-814

FRAILE, Pedro (1998): La retórica contra la competencia en España (1875-1975), Madrid: Fundación Argentaria.

GIL ROBLES, Enrique (1904): "La vuelta a los campos", Revista Católica de Cuestiones Sociales 112, pp. 193-201.

GÓMEZ-FERRER, Guadalupe (2005): "Armando Palacio Valdés y la civilización de su tiempo: la sensibilidad de un novelista", Palacio Valdés: un clásico olvidado (18532003): actas del I Congreso Internacional Armando Palacio Valdés, celebrado en Entralgo (Laviana) los días 24, 25 y 26 de septiembre de 2003, Entralgo (Laviana): Centro de Interpretación Armando Palacio Valdés, pp. 131-166. 
GONZÁLEZ HERRÁN, José Manuel (1996): “Trenes en el paisaje (1872-1901): Pérez Galdós, Ortega Munilla, Pardo Bazán, Pereda, Zola, Alas”, en Villanueva, D., y Cabo, F. (eds.), Paisaje, juego, multiligüismo, Santiago de Compostela: Universidad de Santiago, pp. 345-358.

GONZÁLEZ LÓPEZ, Etelvino (2003): "Demetria ha muerto: el relevo de una cultura o la apostasía de las gentes del campo", Palacio Valdés: un clásico olvidado (18532003): actas del I Congreso Internacional Armando Palacio Valdés, celebrado en Entralgo (Laviana) los días 24, 25 y 26 de septiembre de 2003, Entralgo (Laviana): Centro de Interpretación Armando Palacio Valdés, pp. 167-184.

HIRSCHMAN, Albert O. (1992): "La industrialización y sus múltiples descontentos. El oeste, el este y el sur", Claves de Razón Práctica, n² 25, septiembre, pp. 2-9.

LITVAK, Lily (1980): Transformación industrial y literatura en España (1895-1905), Madrid: Taurus.

LITVAK, Lily (1991): El tiempo de los trenes. El paisaje español en el arte y la literatura del realismo (1849-1918), Barcelona: Ediciones del Serbal.

LLOVERA, José María (1909): Tratado elemental de sociología cristiana, Barcelona: Oficina de Trabajo de la Acción Social Popular.

LLUCH, Ernest (1997): "La arquitectura catalana modernista contra la industrialización", en Bel, Germà, y Estruch, Alejandro (coords.), Industrialización en España. Entusiasmos, desencantos y rechazos, Madrid: Civitas, pp. 183-203.

LLURIA, Enrique (1933)[1906]: La máquina a favor de la humanidad según las leyes naturales, Madrid: Gráficas Socialistas.

MARQUÉS DE VALLE-AMENO (1904): "La Iglesia y la industria. Discurso pronunciado en el Primer Congreso Católico Nacional celebrado en Madrid, 1889", en Discursos acerca de Economía Social, Zaragoza: Librería Agustín Allué.

MARTÍNEZ SAHUQUILLO, Irene (1994): "William Morris y la crítica a la sociedad industrial: una síntesis singular de radicalismo romántico y marxismo", Revista española de investigaciones sociológicas, $\mathrm{n}^{\circ} 66, \mathrm{pp} .171-180$.

MARTÍNEZ VARA, Tomás, y RAMOS GOROSTIZA, J.L. (2012): "El matizado anti-industrialismo del catolicismo social español, 1880-1936", Historia y Política, $\mathrm{n}^{\circ} 27$, enero-junio, pp. 251-279

MARTYKÁNOVÁ, Darina (2007): "Por los caminos del progreso: el universo ideológico de los ingenieros de caminos españoles a través de la Revista de Obras Públicas", Ayer, 68 (4), pp. 193-219.

MAYER, Arno (1981): La persistencia del Antiguo Régimen, Madrid: Alianza.

MONTERO, Feliciano (1983): El primer Catolicismo Social y la "Rerum Novarum" en España (1889-1902), Madrid: CSIC.

MONTERO, Feliciano (2001a): "El catolicismo social en España, 1890-1936", Sociedad y Utopía. Revista de Ciencias Sociales 17, pp. 115-134.

MONTERO, Feliciano (2001b): "La crítica católica de la economía clásica y el primer catolicismo social (Sobre el impacto de la "Rerum Novarum" y la aportación de los católicos españoles al reformismo social)", en Enrique Fuentes Quintana (dir.), Economía y economistas españoles. 5. La críticas a la economía clásica, Barcelona: Galaxia Gutenberg-Círculo de Lectores, pp. 451-493.

MORRIS, William (1977): Arte y Sociedad Industrial. Antología de Escritos, Valencia: Fernando Torres Editor.

MORRIS, William (2004)[1890]: Noticias de ninguna parte, Barcelona: Minotauro. 
ORDÓÑEZ, Javier (2007): "Ingenieros, utopía y progreso en la novela española del Ochocientos", en Silva Suárez, Manuel (ed.), Técnica e Ingeniería en España, IV: El Ochocientos: pensamiento, profesiones y sociedad, Zaragoza: Real Academia de Ingeniería - Institución "Fernando El Católico" - Prensas Universitarias de Zaragoza, pp. 467-514.

PALACIO VALDÉS, Armando (1991)[1903]: La aldea perdida, edición de Álvaro Ruiz de la Peña, Madrid: Espasa Calpe.

PERFECTO GARCÍA, Miguel Angel (2005): "El corporativismo en España: desde los orígenes a la década de 1930", Pasado y Memoria 5, pp. 185-218.

PRETEL O'SULLIVAN, David (2009): “Invención, nacionalismo y progreso: el discurso tecnológico de las clases industriales en la España decimonónica", Empiria, $\mathrm{n}^{\circ} 18$, pp. 59-83.

PIÑERA, Ismael (2005): "Palacio Valdés en la encrucijada metodológica de la adaptación cinematográfica", Palacio Valdés: un clásico olvidado (1853-2003): actas del I Congreso Internacional Armando Palacio Valdés, celebrado en Entralgo (Laviana) los días 24, 25 y 26 de septiembre de 2003, Entralgo (Laviana): Centro de Interpretación Armando Palacio Valdés, pp. 245-282.

POLLARD, Sidney (1971): The idea of Progress, Londres: Penguin Books.

PONCE, Juan Carlos (1996): Literatura y ferrocarril en España: aspectos socio-literarios del ferrocarril en España, Madrid: Fundación de los Ferrocarriles Españoles.

RAMOS GOROSTIZA, José Luis (2008): "El descontento frente a la ciudad industrial: reformismo social y "ciudad jardín" en España, 1900-1923", Revista de Historia Industrial, $\mathrm{n}^{\circ} 37$, pp. 85-122.

RAMOS GOROSTIZA, J.L., y MARTÍNEZ VARA, Tomás (2011): "El anti-industrialismo en España, 1870-1936", Alcores. Revista de Historia Contemporánea, n 11, pp. 267-289.

RIERA, Carmen (1988): "Gabriel Miró y el movimiento prerrafaelista", 1616: Anuario de la Sociedad Española de Literatura General y Comparada, Vol. VI-VII, pp. 141-148.

RODRÍGUEZ DE CEPEDA, Rafael (1887): Elementos de Derecho Natural, I, Valencia: Imprenta Doménech.

RODRÍGUEZ DE CEPEDA, Rafael (1891): Las clases conservadoras y la cuestión social, Madrid: Sociedad Editorial de San Francisco de Sales.

RODRÍGUEZ FELGUEROSO, Alberto (2005): "La organización agraria tradicional en la obra asturiana de Armando Palacio Valdés", Palacio Valdés en Asturias: actas del II Congreso Internacional Armando Palacio Valdés y su Obra, celebrado en Entralgo (Laviana), los días 4, 5, 6 y 7 de octubre de 2005. Entralgo (Laviana): Centro de Interpretación Armando Palacio Valdés, pp. 305-328.

ROMERO, Leonardo (2003): "La aldea perdida en la trayectoria de la novela moderna. De la novela realista a la novela intelectual", Palacio Valdés: un clásico olvidado (1853-2003): actas del I Congreso Internacional Armando Palacio Valdés, celebrado en Entralgo (Laviana) los días 24, 25 y 26 de septiembre de 2003, Entralgo (Laviana): Centro de Interpretación Armando Palacio Valdés, pp. 303-314.

RUBIO COLOMA, J. (1916): "La vida en el campo", Revista Católica de Cuestiones Sociales 253, pp. 12-14.

RUIZ DE LA PEÑA, Álvaro (2003): "Introducción" a Palacio Valdés, A., La aldea perdida, Madrid: Espasa Calpe, pp. 9-46.

RUSKIN, John (2002): A este último. Cuatro ensayos sobre los principios básicos de la 
economía política [1860], Salobreña (Granada): Alhulia.

SANZ DE DIEGO, Rafael (1979): "La iglesia española ante el reto de la industrialización”, en Cárcel Ortí, Vicente (dir.), Historia de la Iglesia en España. V. La Iglesia en la España Contemporánea (1898-1875), Madrid: Biblioteca de Autores Cristianos, pp. 577-664.

SILVESTRE, J., y SERRANO, E. (2001): "La representación en el cine de la integración de los inmigrantes rurales en las ciudades. El pesimismo de Surcos", Ager 3, pp. 126.

TRINIDAD, Francisco (2005): "Asturias y lo asturiano en La aldea perdida", Palacio Valdés en Asturias: actas del II Congreso Internacional Armando Palacio Valdés y su Obra, celebrado en Entralgo (Laviana), los días 4, 5, 6 y 7 de octubre de 2005. Entralgo (Laviana): Centro de Interpretación Armando Palacio Valdés, pp. 365-384.

VELASCO, Carlos (1982): "El pensamiento agrario y la apuesta industrializadora en la España de los cuarenta", Agricultura y Sociedad, $\mathrm{n}^{\circ} 23$, pp. 233-273.

WIENER, Martin J. (1981): English culture and the decline of the industrial spirit 18501980, Cambridge: Cambridge University Press. 
